\section{LA ANTROPOLOGÍA DE JACQUES MARITAIN: PROBLEMAS $Y$ VIRTUALIDADES DE LA DISTINCIÓN INDIVIDUO - PERSONA}

\author{
Manuel López-Casquete de Prado \\ Universidad Loyola Andalucía \\ mlopezcasquete@gmail.com
}

\begin{abstract}
Cómo citar este artículo/Citation: López-Casquete de Prado, M. (2014). "La antropología de Jacques Maritain: problemas y virtualidades de la distinción individuo - persona". Arbor, 190 (769): a167. doi: http://dx.doi.org/10.3989/ arbor.2014.769n5006
\end{abstract}

Recibido: 9 octubre 2013. Aceptado: 24 junio 2014.

RESUMEN: Una de las reivindicaciones más repetidas en la actual reflexión académica en ámbitos tan dispares como la economía, la sociología, la bioética, el derecho o la política, plantea la necesidad de reconfigurar nuestras instituciones desde una antropología más humanizadora y, por tanto, más orientada a posibilitar la felicidad de la población. Entre las distintas aproximaciones teóricas utilizadas para concretar esta reivindicación, cada vez cobra más fuerza la que pretende recuperar y actualizar la clásica distinción tomista entre individuo y persona. Una de las formulaciones más sistemáticas y clarificadoras a este respecto es la ofrecida por el filósofo francés Jacques Maritain. En este artículo se realiza un análisis crítico de su planteamiento antropológico y se concluye que, con luces y sombras, el sistema de Maritain puede ser de gran interés para profundizar en este debate social y contribuir así a reelaborar nuestras bases antropológicas de modo que podamos alumbrar una sociedad a la medida de la persona y sus fines.

PALABRAS CLAVE: Humanización; personalidad; felicidad; personalismo; sociabilidad.

\section{JACQUES MARITAIN'S ANTHROPOLOGY: PROBLEMS AND VIRTUALITIES OF THE INDIVIDUAL - PERSON DISTINCTION}

Copyright: ( 2014 CSIC. Este es un artículo de acceso abierto distribuido bajo los términos de la licencia Creative Commons Attribution-Non Commercial (by-nc) Spain 3.0.

ABSTRACT: Modern academic thinking in fields as diverse as economics, sociology, bioethics, law or politics frequently calls for a reconfiguration of our public institutions from a more humanising anthropological perspective to make them more conducive to people's happiness. Among the approaches used to focus on this demand, the Thomist distinction between the individual and the persona has come to the fore. One of the most systematic and enlightening theories in this regard is that of French philosopher Jacques Maritain. In this paper we analyse his anthropological approach to conclude that, with positive and negative aspects, it may be of great interest approach to deepen this social debate and so help develop a new anthropological theory more geared towards people and their goals.

KEYWORDS: Humanisation; personality; happiness; personalism; sociability. 


\section{INTRODUCCIÓN}

Cada vez es más frecuente, en ámbitos de conocimiento tan dispares como la economía, la sociología, la bioética, el derecho o la política, la expresión de la idea de que es necesario abordar una reconfiguración de nuestras instituciones sociales, de modo que puedan contribuir a mejorar la felicidad de las personas. Una de las bases teóricas desde la que se está pretendiendo abordar dicho rediseño apunta a la recuperación de la distinción entre individuo y persona, cuya raíz se remonta a la obra de Santo Tomás de Aquino. Citamos algunos ejemplos provenientes de diversos ámbitos de conocimiento:

- La tradición de raíz italiana denominada economía civil parte de la idea de que resulta urgente reelaborar una reflexión sobre el papel de la persona humana en el discurso económico, porque el concepto de individuo en el que se basa esta ciencia es mucho más limitado que el de persona, e incapaz de dar respuesta a los retos de la época actual. Es preciso, por tanto, reconsiderar los postulados antropológicos del discurso económico (Zamagni, 2012).

Las bien conocidas teorías de los contratos, de la empresa, de los precios, etc., no tienen ninguna necesidad de recurrir a la categoría de persona: basta el individuo informado y racional. [...] Si acierto en lo que digo, me parece descubrir en los desarrollos más recientes de la teoría económica un interés genuino con relación al paradigma relacional centrado en la idea de persona (Zamagni, 2006, pp. 37-38).

- Del mismo modo, cuando Bruni y Zamagni (2004, p. 240) describen el principio de subsidiariedad, lo explican como emanación di un altro principio, quello personalista, che ci dice che l'essere umano non è solo individuo (realtà distinta e autosufficiente) ma è soprattutto persona, cioè diventa pienamente se stesso nel rapporto di reciprocità con l'altro. Es decir, también en este punto los autores apelan a la distinción entre individuo y persona para alumbrar un rediseño de la antropología sobre la que se basa la investigación económica.

- También en el ámbito de la economía, Alford (2007, p. 11) plantea que el personalismo puede ayudarnos a ir más allá de las debilidades del individualismo sin perder sus ventajas, ya que esta línea filosófica reconoce la importancia del individuo sin ser individualista. Es decir, el personalismo ofrece un balance equilibrado entre la atención al individuo (cuyos fines propios toma en consideración) y la dimensión colectiva humana (ya que parte de la convicción de que solo el aspecto relacional ofrece al hombre la posibilidad de desarrollarse como persona). Desde esta perspectiva se considera al otro no solo como contraparte de un contrato o acuerdo diseñado para mutuo beneficio, sino como parte de nosotros mismos. Partiendo de la conceptualización mariteniana de la persona, Alford plantea la necesidad de una nueva comprensión socioeconómica basada en la ontological relationality.

- En el campo de la bioética, Raúl Mesa García (2010) también basa su planteamiento en la distinción entre persona e individuo, y Jiménez Garrote (2006) elabora sus argumentos basándose en el planteamiento personalista de Maritain. En España, es preciso destacar en esta línea los trabajos de Juan Manuel Burgos Velasco (1995, 2006 y 2007).

- En el ámbito de la sociología, Gattamorta (2012, p. 85) afirma que se precisa un modelo socio-antropológico que evite el peligro de que, a pesar de estar referido a lo humano, pierda de vista a la persona. En la misma línea, Martigniani (2012, p. 101) plantea la necesidad de ripensare la dimensione umana come radice dell'ontologia sociale in base al recupero del concetto di persona. En general, podemos afirmar que los trabajos de reivindicación del concepto de persona en la sociología actual son muy abundantes -algunos ejemplos son: Gruppo Spe (2007), Allodi y Gattamorta (2008), Cahill (1997), Archer (2000), Hirschhorn (2007)-.

Por todo lo anterior, nos parece pertinente ofrecer una revisión crítica de la distinción entre individuo y persona en Jacques Maritain, ya que este filósofo ofrece uno de los enfoques más sistemáticos y clarificadores a este respecto. Con luces y sombras, el planteamiento de Maritain puede ser de gran interés para profundizar en este debate social. Para ello, comenzaremos situándolo en el contexto del que surge: el movimiento personalista francés del siglo XX (epígrafe 2). A continuación, analizaremos la pertinencia de las críticas esgrimidas contra el sistema antropológico de Maritain, especialmente la relativa a una excesiva escisión entre individuo y persona, que incluso resulta trasladada en la obra del filósofo francés al plano ontológico (epígrafe 3). Una vez clarificada esta cuestión, expondremos cuáles son a nuestro juicio los elementos positivos de esta distinción en el sistema mariteniano (epígrafe 4). Por último, entramos a detallar cuál es el contenido de la personalidad según Maritain, siguiendo tres de los aspectos tratados en su obra con más profusión: sociabilidad, libertad y amor (epígrafe 5). 


\section{EL FENÓMENO PERSONALISTA}

Si algo está claro en la obra de Jacques Maritain es que el punto de partida de todo su sistema es su concepción antropológica:

Mais rationaliser l'humain sans savoir ce qu'est I'homme, ce n'est plus possible. [...] II faut donc savoir ce qu'est l'homme: office de métaphysique! (Maritain, 1933, pp. 334-335).

En la misma línea se pronuncia Lorenzini, quien considera que la antropología mariteniana subyace a todos los temas propuestos en su extensa obra:

Non è esagerato affermare che l'antropologia è il punto centrale e continuamente ricorrente della sua ricerca. La concezione che Maritain propone dell'uomo sottostà dunque a tutte le tematiche che nelle sue opere vengono proposte (Lorenzini, 1992, p. 164).

Sin embargo, a pesar de la importancia de la antropología en el filósofo francés, no ofrece un tratamiento sistemático de la cuestión, sino que debe rastrearse a lo largo de su extensa obra (Burgos, 2006, p. 79). La concepción antropológica de Maritain se incardina en el personalismo francés que nació en los años 30 del siglo XX de la mano de Emmanuel Mounier, quien lo popularizó a través de la revista Esprit. Para Juan Manuel Burgos, las aportaciones intelectuales más importantes de esta línea de pensamiento consisten en remarcar la centralidad de la persona; servir de freno tanto a las tendencias totalizadoras del marxismo y del nazismo como al individualismo exacerbado; haber puesto en circulación una serie de conceptos anteriormente desatendidos en algunos ámbitos de reflexión filosófica: amor, donación, diálogo, relaciones interpersonales, etc. (Burgos, 1997, p. 143). Al listado aportado por Burgos habría que añadir la oposición que ejerció este movimiento a la actitud cientificista derivada del positivismo.

El aspecto central del surgimiento del personalismo en la revista Esprit es que el término persona se ofrece como el punto de referencia de su acción, desde un cierto sentido de urgencia y de testimonio en una Francia convulsa, para rehacer el cogito cartesiano desde las coordenadas de la persona. Sin embargo, es casi tautológico plantear que el personalismo se basa en la centralidad de la persona. La cuestión clave, por tanto, es dilucidar el modo en que se establece esa centralidad en el personalismo, y qué consecuencias se derivan de ello. La centralidad de la persona se puede plantear en dos sentidos (Burgos, 1997, p. 148): ${ }^{1}$
- Centralidad genérica: según este planteamiento, se reconoce al hombre un valor y una dignidad esenciales, lo cual marcaría de modo definitivo la elaboración filosófica en los ámbitos social, político, histórico... Existen muchas filosofías basadas en este planteamiento, y desde luego cualquiera que se ofrezca como compatible con el cristianismo.

- Centralidad estructural: esta opción va más allá de la mencionada centralidad genérica de la persona, de modo que la reflexión filosófica se construye técnicamente alrededor de este concepto. Es decir, la persona no es solo una realidad relevante, sino el elemento de experiencia y la noción de la que depende y alrededor de la cual se construye el andamiaje conceptual de este tipo particular de filosofía (Burgos, 1997, p. 148). El movimiento personalista se sitúa claramente en esta perspectiva.

Existe un sector neoescolástico que rechaza la posición personalista bajo la crítica de que modifica puntos esenciales de su sistema (Burgos, 1997, p. 146). En la raíz de esta oposición se sitúa cierta falta de neutralidad ideológica presente en el personalismo, ya que, como sabemos, surge como un fenómeno de oposición a determinadas construcciones socio-políticas. Pero, sin embargo, el vínculo entre el personalismo y la neoescolástica es evidente, ya que ambas tradiciones se orientan esencialmente desde la centralidad de la persona.

¿En cuál de estas dos visiones de la persona debemos situar la filosofía neoescolástica? Según Burgos, la neoescolástica es personalista en sentido genérico, ya que concede relevancia a la persona, pero no se estructura técnicamente alrededor de ella y de su conceptualización filosófica, sino según otros conceptos, como los de potencia-acto y sustanciaaccidentes. Desde el punto de vista especulativo, la persona es una realidad secundaria que se explica precisamente a través de una particular combinación y caracterización de este conjunto de categorías (Burgos, 1997, p. 148).

Julián Marías también avala este planteamiento:

Cuando, ya en la escolástica, se ha intentado pensar filosóficamente la persona, las nociones que han sido decisivas no son las procedentes de estos contextos, sino las de "propiedad" o "subsistencia" (hypóstasis). La famosa definición de Boecio, tan influyente -persona est rationalis naturae individua substantia- $h a$ partido de la noción aristotélica de ousía o substantia, pensada primariamente para las "cosas" [...]. El que esta sustancia o cosa que llamamos "persona" sea ra- 
cional será sin duda importante, pero no lo suficiente para reobrar sobre ese carácter de la ousía y modificar su modo de ser, su manera de realidad. La persona es una hypóstasis o suppositum como los demás, solo que de naturaleza racional (Marías, 1987, p. 41).

La particularidad del sistema de Maritain es que, aunque se incardina claramente en la tradición tomista, en cambio se orienta desde la mencionada centralidad estructural. Nos parece clara dicha centralidad estructural en el sistema mariteniano, puesto que elabora toda su construcción teórica desde su comprensión de la persona. Veamos algunos ejemplos:

- En el artículo Qu'est-ce que l'homme? (Maritain, 1945), el autor francés plantea que cada gran período de civilización ha estado dominado por la imagen que el hombre tenía de sí mismo en ese momento, ya que esto determina nuestra conducta y nuestras instituciones socio-políticas. En esa misma obra plantea que, por consiguiente, toda posibilidad de regeneración de la comunidad humana pasa por redescubrir la verdadera imagen del hombre.

- En otra obra, Les droits de l'homme et la loi naturelle (Maritain, 1942), el filósofo afirma que una sana concepción política depende ante todo de la consideración de la persona humana.

Esta particularidad de la obra de Maritain como elaboración innovadora y creativa del tomismo ha sido subrayada por numerosos autores. Así, para Álvarez:

La hermenéutica maritainiana del tomismo, sin embargo, no sigue los cánones más comunes y, por ello, se ha discutido mucho sobre su ortodoxia. De lo que se trata, para nuestro filósofo, es de ser fiel al espíritu tomista e innovar a partir de su verdad, no de repetir una y otra vez, vanamente, su letra. De ese modo, la tarea renovadora que se propuso y que no siempre fue bien entendida y aceptada, se nos muestra en toda su complejidad: intenta "sacar al tomismo de su encasillamiento histórico o de los manuales de seminario para hacer de él una filosofía viva" (Álvarez, 2007, p. 567).

El sentido que Maritain atribuye al fenómeno personalista es el de ofrecerse como reacción contra dos errores opuestos: el individualismo liberal-burgués y los totalitarismos. Por ese motivo, dice Maritain:

II n'y a pas une doctrine personnaliste, mais des aspirations personnalistes et une bonne douzaine de doctrines personnalistes, qui n'ont parfois en commun que le mot de personne, et dont certaines penchent plus ou moins vers l'une des erreur contraires entre lesquelles elles se situent. II y a des personnalismes à tendance nietzschéenne et des personnalismes à tendance proudhonienne, des personalismes qui penchent vers la dictature et des personalismes qui penchent vers l'anarchie. Un des grands soucis du personnalisme thomiste est d'eviter l'un et l'autre excès (Maritain, 1947, p. 170).

Como se desprende de este párrafo, el propio autor sitúa su elaboración antropológica en la matriz tomista, a la cual considera el modo más adecuado de comprensión del fenómeno personalista; sin embargo, como hemos visto, la centralidad de la persona en Maritain no es meramente genérica, como en la tradición tomista, sino estructural. Por este motivo, para Burgos, la obra de Maritain representa una tarea de mediación entre el tomismo y algunas instancias personalistas. $Y$ son precisamente estos elementos novedosos los causantes de una parte de los debates intelectuales y polémicas en los que se vio envuelto (Burgos, 1997, p. 146).

En cualquier caso, el carácter tomista de la elaboración antropológica de Maritain aparece de modo evidente si tenemos en cuenta que, como él mismo plantea en Du régime temporel et de la liberté (Maritain, 1933), la piedra angular de toda su elaboración antropológica se basa en la clásica distinción tomista entre individuo y persona:

- El concepto de individuo remite a la idea de especificación dentro de un conjunto. La categoría de individuo no es en sí negativa, ya que es condición de posibilidad de nuestra existencia; ella sitúa a cada ser humano en el espacio y lo diferencia del resto. En el sistema mariteniano, el concepto de individuo atiende a la relación del hombre con el mundo sensible; es decir, es la dimensión material la que ofrece la base ontológica al individuo. Ya que el concepto de individuo remite a un conjunto mayor, el bien particular de cada individuo está subordinado al bien común colectivo, puesto que ningún individuo puede pretender que prevalezcan sus intereses por encima de los del conjunto.

- El concepto de persona, por su parte, no remite ya a un conjunto mayor, sino a la idea de totalidad e independencia de cada ser humano. De este modo, la persona es entendida como un microcosmos que contiene en sí todo el universo (Maritain, 1942, p. 188). La personalidad confiere a cada ser humano valor en sí mismo, derechos y dignidad inalienable. Maritain sitúa la raíz ontológica de la personalidad en la subsistencia del espíritu. Ya que la persona es entendida 
como un todo independiente, el bien común de la ciudad queda subordinado a su destino intemporal.

\section{UNIDAD O DUALIDAD}

El propio Maritain aclara que no existe separación entre individualidad y personalidad: cada uno de nosotros es un único ser que en un sentido es individuo y en el otro es persona. Sin embargo, este planteamiento contiene algunas dificultades especulativas que han sido criticadas por algunos autores, como Lorenzini: Persona e individuo non sono semplicemente uniti, ma identici: dire persona umana è la stessa cosa che dire individuo umano. Se non si comprende questo si rischia di concepire la relazione persona-individuo come una relazione atto-potenza (Lorenzini, 1992, p. 167).

También Juan Manuel Burgos plantea que en Maritain existe una tendencia dualista entre personalidad e individualidad, en la que categoriza esta última de modo excesivamente negativo. Desde esta dualidad, Maritain traslada la lucha del hombre consigo mismo al terreno ya no moral, sino ontológico, puesto que para el filósofo francés la individualidad representa el egoísmo y la búsqueda de sí, mientras que la personalidad representa el don de sí, el amor y lo espiritual (Burgos, 2006, p. 79).

En síntesis, consideramos que estas críticas no están exentas de razón, aunque es necesario matizarlas. Desde una primera aproximación, no nos parece tan claro que en Maritain exista escisión entre individuo y persona; al contrario, ambas categorías remiten a distintos modos de considerar al ser humano. Así, desde una perspectiva arraigada en lo material, se contempla al hombre simplemente como individuo distinto del resto; por el contrario, si el ser humano es visto desde una perspectiva atenta a lo espiritual, lo estaremos contemplando como persona.

Esta es también la comprensión de la antropología de Maritain de Louis Chamming's (ex-presidente del Cercle d'études Jacques et Raïssa Maritain), para quien Caractériser l'homme comme individu, c'est le considérer du côté de la matière; le caractériser comme personne, c'est le considérer dans sa dimension spirituelle (Chamming's, 2007, p. 65).

También para Curcio, la comprensión de la personalidad como subsistencia del espíritu es el eje sobre el que se articula la concepción antropológica de Maritain, ya que conduce a una unidad profunda entre intelecto y voluntad en la búsqueda de un único fin, fondamento di tutto l'agire umano in cui la libertà rappresenta il punto cardine, non solo della filosofia della persona, ma anche di quella morale e politica (Curcio, 2010, p. 40).

El problema especulativo -como plantean Burgos y Lorenzini- estriba en que, en algunos pasajes de la obra de Maritain, el individuo es considerado como acto y la personalidad como potencia. El paso indebido en la elaboración del filósofo francés resulta evidente, ya que es imposible plantear la relación entre cuerpo y espíritu como una relación de potencia-acto, puesto que nuestra materialidad no puede devenir espiritualidad.

Para Maritain, la noción de persona es analógica, y se realiza en grados diversos y sobre planos ontológicos esencialmente distintos (Botturi, 1994, p. 9). ${ }^{2}$ De este modo, para Maritain, el hombre será tanto pura persona como sea pura inteligencia, siendo Dios el único a quien se puede aplicar la condición de pura persona. Como comenta De Finance (1955, p. 74), en Maritain la persona aparece como un ser que, situado por su naturaleza en un ámbito definido de ser, supera en algunos aspectos sus propios límites para acceder al orden de la totalidad. Esta apreciación nos parece problemática por la sencilla razón de que, como afirma Lorenzini, è sbagliato ritenere che la nozione di persona escluda quella di materia. Por eso estamos de acuerdo con ella en que no tiene sentido utilizar términos como "pura persona" o "no pura persona", exactamente igual que no tiene sentido referirse a "puro sujeto" o "no puro sujeto". Lo contrario sería plantear que el horizonte del ser humano fuera el de trascender su propia materialidad, compiendo un indebito passaggio dal piano logico a quello ontologico (Lorenzini, 1992, p. 184). En lugar de esto, como afirma Curcio, hay que entender que el acto de ser que pertenece al alma por prioridad ontológica es también el acto de ser que confiere actualidad al cuerpo (Curcio, 2010, p. 41).

En la misma línea, Zanotti explica que Maritain es aquí víctima de haber seguido el principio de individuación por el lado de la materia signada por la cantidad, sin advertir que para Santo Tomás toda creatura es individual, siendo ello ontológicamente anterior a que sea material o no (Zanotti, 2012, p. 123). El propio Zanotti añade que no duda de las referencias al corpus tomista en las que se apoya la antropología de Maritain, sino de la correcta interpretación de estas, ya que, para Santo Tomás, persona humana es persona individual, e individuo humano es persona humana (Zanotti, 2012, p. 123). 
La objeción parece clara: Maritain atribuye a la personalidad el carácter expansivo y comunicativo del hombre, mientras que sitúa en la individualidad su tendencia centrípeta y egoísta. Esto, para Botturi, supone enmascarar la complejidad paradójica de la subjetividad humana; para el filósofo francés -continúa Botturi-, la individualidad hace que el hombre se contraponga al resto de hombres, mientras que la personalidad remite a una comunicación esencial con el resto de personas en tanto que son individuaciones de lo trascendente. De este modo, la individuación se convierte para Maritain en un auténtico estado de alienación por oposición a la riqueza trascendente distribuida entre todos los seres humanos (Botturi, 1994, pp. 11-12).

Dicho con otras palabras, la objeción que hacemos a Maritain es que, en su planteamiento, confunde la idea de superar el mundo material con la de superar la naturaleza humana. Aún siguiendo a Lorenzini,

La perfezione di ogni ente consiste nell'esercizio della sua operazione propria, dell'operazione che è proporzionata alla sua natura. [...] Inoltre, nell'esercizio dell'operazione propria, l'uomo (come ogni altra creatura) non tende a diventare Dio, ma tende alla realizzazione secondo la propria natura di una somiglianza con Dio (Lorenzini, 1992, p. 185).

Y también Zanotti:

Esta cuestión ha quedado muy desatendida en un tomismo que se aferra nada más que a la individuación según está tratada por Santo Tomás en De Ente et Essentia, donde se afirma que el principio de la individuación de la sustancia corpórea es la materia signada por la cantidad, quedando siempre la pregunta de cómo un accidente, la cantidad, que recibe su ser de la sustancia (que por ende tiene una analogía de proporción con la sustancia donde esta última es el analogante) puede ser al mismo tiempo causa de la individuación de la sustancia, cuando se supone que el accidente recibe su ser individual de la sustancia individual (Zanotti, 2012, p. 134).

En suma, consideramos que el planteamiento de Maritain resulta problemático en todos aquellos pasajes en los que describe el proceso de desarrollo de la personalidad como un proceso transnatural; es decir, en aquellos pasajes de su obra en los que se plantea que el desarrollo de la personalidad consiste en trascender nuestra materialidad en aras de nuestra espiritualidad. No obstante lo anterior, y por situar esta polémica en términos justos, hay que decir que en otros pasajes de la obra de Ma- ritain la relación potencia-acto es entendida como un proceso de desarrollo de la personalidad abierto y dinámico, sin que se establezca ninguna brecha ontológica entre individualidad y personalidad. Al contrario, el proceso de desarrollo personal es planteado como un camino de apertura espiritual contrariado por las miserias de la individualidad material, es decir, por el reclamo de la avidez propia de nuestra naturaleza material. Así, en De Bergson a Tomás de Aquino (Maritain, 1946, pp. 189-190), afirma que no nos referimos a la persona que soy yo, sino a la persona que hay en mí. De este modo Lorenzini podría convenir con Maritain -esta vez síque la personalidad está en el hombre, pero no es propiamente humana, sino que, en tanto que subsistencia del espíritu, es también subsistencia en nosotros de Dios.

En cualquier caso, y aunque esta segunda conceptualización nos parece más acertada, no podemos obviar que en este apartado se aprecian ciertas incoherencias en el planteamiento antropológico de Maritain. Así, en algunas obras, la individualidad es presentada como un aspecto negativo (como indigencia, egoísmo y materialidad) y en otros pasajes es considerada como positiva (condición de posibilidad de nuestra existencia). Con otras palabras, algunas reflexiones antropológicas del autor se articulan desde un mismo plano ontológico (en el que la persona está llamada a trascender lo material para situar su centro en lo espiritual), mientras que en otras se conceptúa este proceso de desarrollo como el paso a un plano ontológico distinto. Esta segunda perspectiva es claramente inaceptable.

Otra crítica a la concepción antropológica del filósofo francés (Botturi, 1994, p. 11) plantea que Maritain deja en penumbra el carácter de unidad indivisa e indivisible -es decir, de individualidad- de la dimensión espiritual y por tanto de la condición personal del hombre. Por este motivo, habría sido más correcto referirse al hombre en tanto que ser corpóreo como individuo individuado, y en tanto que ser espiritual como individuo personal. De este modo se habría mantenido la evidencia de la comunión transcendental humana tanto en su condición de persona como en su condición de individuo singular específico. En nuestra opinión, aún habría sido mejor utilizar una terminología que evitase toda sospecha de dualidad, como sucede, por ejemplo, en la obra de Jean Lacroix, que hace referencia a los conceptos de persona individuada o espíritu encarnado (Lacroix, 1942, pp. 129-130). 


\section{VIRTUALIDADES DE LA DISTINCIÓN INDIVIDUO - PERSONA}

A pesar de estas dificultades especulativas, una correcta comprensión de la antropología de Maritain debe llevarnos a entender que, en su sistema, la individualidad es buena en orden a la personalidad, por lo que debe estar subordinada a esta y a sus fines. En cambio, dar preponderancia a la individualidad es un error, porque nos dispersa del centro supremo al que tiende la persona, y que en el sistema mariteniano es la dimensión espiritual como aproximación a Dios. Sin embargo la individuación es necesaria, nos sitúa en el espacio y en el tiempo, y su toma en consideración sirve al filósofo para atender a la naturaleza de un espíritu encarnado y no puramente angélico. De este modo, y de forma reiterada a lo largo de su extensa obra, Maritain establece una clara línea jerárquica: como individuo ( $y$, por tanto, en el orden práctico-temporal o cosas del César), el ser humano queda subordinado al conjunto; pero el conjunto, a su vez, queda subordinado a la persona y debe orientarse al servicio de los fines últimos de esta (que son de orden supratemporal o cosas de Dios). Esto no debe llevarnos a entender que Maritain desprecia el bien temporal de la persona, sino que lo subordina en importancia al bien supratemporal. En este sentido afirma en Du régime temporel et de la liberté (Maritain, 1933) que, aunque los avances técnicos son positivos, estos deben subordinarse a la persona y a sus auténticos fines. En caso contrario, conducen a la infelicidad desesperanzada.

Toda tentativa de dar sentido a los acontecimientos en función de un pensamiento o acción social o política presupone necesariamente una filosofía de la historia, aunque sea de forma implícita. Este es también el esquema dialéctico de Maritain, donde la visión antropológica expresa una absoluta coherencia con la comprensión histórica. Para el filósofo francés, si el siglo XIX asistió a los errores del individualismo y en el siglo XX el comunismo reaccionó oponiendo al individualismo un planteamiento exclusivamente comunitario, ahora es preciso oponer a estas concepciones opuestas la noción de persona humana (Maritain, 1947). Esa es, para Maritain, la tarea del personalismo (Chamming's, 2007, p. 61).

La doble posibilidad de aproximación al ser humano -como individuo y como persona- sirve a Maritain para revelar las graves carencias antropológicas de que adolecen determinados modos de construcción sociopolítica que solo atienden a las condiciones materiales del hombre (su individualidad) y dejan al margen los aspectos relacionados con la pervivencia del espíritu (su personalidad), con consecuencias devastadoras en lo relativo al respeto a la dignidad humana y a los fines que le son propios. Si el filósofo francés insiste más en definir la personalidad que la individualidad es porque aquélla supone una visión más completa del ser humano. Para expresarlo claramente $(y$, una vez más, prescindiendo de las ya mencionadas críticas especulativas), situarnos en la perspectiva de la individualidad o de la personalidad tiene que ver con el modo subjetivo desde el que nos aproximamos al hombre, y no con el propio hombre como objeto. Así, una visión centrada en la individualidad deja de percibir una gran parte de lo que significa ser humano.

Así sucede en el individualismo liberal burgués, el fascismo o el marxismo, que solo toman en consideración el aspecto material-individual del hombre. Si un sistema solo atiende a los fines del individuo, conduce al anarquismo o al materialismo liberal burgués. Por el contrario, si atiende solo al bien común de los individuos, sin tener en cuenta a la persona, conduce a totalitarismos de corte colectivo. Frente a ambos extremos, Maritain reivindica el bien común de la persona humana como fin último de la sociedad. Trasladando el mismo planteamiento a los sistemas democráticos, Maritain considera que el drama de las democracias modernas estriba en el desconocimiento de esta distinción, ya que han buscado construir la ciudad de la persona bajo el error de confundirla con la ciudad del individuo. La idea de democracia de Maritain, por contra, es la de una democracia de la persona, concretada en hábitos y estructuras sociales que permitan la participación de todos en el bien común y en la que la fraternidad quede incorporada a la vida política. Sin fraternidad, dice Maritain en Christianisme et démocratie (Maritain, 1943), la experiencia política queda indefensa frente a la tendencia egoísta presente en el ser humano. La fraternidad, en cambio, nos permite franquear las puertas cerradas de nuestro grupo para abrirnos a todo el género humano. De este modo se superarían los antagonismos de clase y los totalitarismos, y se podría avanzar más allá de capitalismo y socialismo, ya que ambos parten de una concepción materialista de la vida, para construir la auténtica ciudad del hombre.

\section{CONTENIDO DE LA PERSONALIDAD EN JACQUES MARITAIN: SOCIABILIDAD, LIBERTAD Y AMOR}

De entre los múltiples aspectos que conforman el concepto de persona en la obra de Maritain, hemos seleccionado los que nos parecen más significativos y definitorios: sociabilidad, libertad y amor. Aunque 
estos tres aspectos no agotan el contenido del término, consideramos que son los que mejor ayudan a comprender su sentido y alcance en el sistema mariteniano.

\subsection{Sociabilidad}

Según Maritain (1947), tanto desde el enfoque individual como desde el personal, el ser humano necesita de la sociedad:

- Según nuestras necesidades como individuo (morales, educativas, de mutua ayuda...) necesitamos a la sociedad para que nos provea de las condiciones que precisamos para existir y desarrollarnos. Algunas de estas necesidades, como la educación, remiten a un proceso historizado y progresivo.

- Según la personalidad, necesitamos la vida en sociedad en virtud de las perfecciones que nos son propias, particularmente de nuestra necesidad de apertura y sobreabundancia del amor que exige entrar en relación con otros.

Lorenzini matiza acertadamente este planteamiento al sostener que las concreciones históricas derivadas de la sociabilidad natural humana apelan a perfecciones accidentales y no a su esencia sustancial. De ahí que, a pesar de las enormes diferencias entre los sistemas sociales de las distintas culturas y épocas históricas, todos compartamos una idéntica e inmutable esencia humana. Por eso el hombre jamás puede ser reducido a aquello que hace o a su dimensión social o histórica (Lorenzini, 1994, pp. 180-181). Y por el mismo motivo, no todo proceso histórico o dinámica social es sinónimo de progreso humano. De este modo, Maritain puede criticar al marxismo su planteamiento de que el progreso se realice necesariamente en el devenir histórico. De fondo se encuentra la clásica distinción tomista entre ut natura y ut ratio: en este sentido, las concreciones sociales serían obras de la razón (ut ratio, y por tanto contingentes), y no de la naturaleza (ut natura, y por tanto necesarias).

Otro aspecto interesante para alumbrar la sociabilidad humana desde la distinción individuo-persona en Maritain tiene que ver con el proceso comunicativo. Desde esta perspectiva, el hombre necesita de ayuda para recibir los conocimientos necesarios para conducir su existencia; como plantea Santo Tomás en su De regimine principium, est igitur necessarium homini, quod in multitudine vivat (Aquino, 1971a, tomo I, libro 1, pp. 1-2). El conocimiento racional, por tanto, proviene de la comunicación social, que de este modo, como afirma Botturi, se convierte en catego- ría sintética del principio constitutivo de la sociedad humana (Botturi, 1994, p. 14). Esto hace del hombre, en palabras de Santo Tomás, magis communicativus respecto a los demás animales, ya que puede expresarse a través de universales en lugar de limitarse a comunicar las pasiones comunes con el resto de sus semejantes. Se trata aquí de la distinción de raíz aristotélica entre phoné y logos, mediante la cual se muestra la mayor sociabilidad humana respecto al resto de animales.

Esto significa que el hombre puede trascender el puro estado subjetivo, de modo que puede generar mediante la comunicación social la idea común de lo que es justo e injusto y de lo que debe ser la familia o la ciudad (koinonia). Por eso, Santo Tomás puede afirmar con Aristóteles que communicatio in istis facit domum et civitatem. Igitur homo est naturaliter animal domesticum et civile (Aquino, 1971b, tomo I, libro 1, pp. 112-155). El lenguaje se convierte, por tanto, en la concreción de la relacionalidad humana, y revela al mismo tiempo la propia ontología de la persona (Botturi, 1994, p. 16). La ventaja del argumento comunicativo es que se ofrece como síntesis de la doble polaridad humana (individuo - persona), ya que la comunicación expresa la necesidad social del hombre desde ambas perspectivas: como contenido en el caso de la individualidad material y como forma desde la perspectiva de la racionalidad personal (Botturi, 1994, p. 16). Así, la comunicación puede ser entendida como expresión de la generosidad radical de la persona, por la cual tiende a sobreabundar en la comunicación social.

Algunas de las más actuales líneas de trabajo en sociología también apuntan a la comunicación como vía de articulación de la relacionalidad humana. Así, por ejemplo, la controversia entre Mead y Schütz sobre si el proceso comunicativo es el fundamento de la relación social o viceversa (Gattamorta, 2012, p. 95). En la misma línea, la ética del discurso de Apel y Habermas plantea que la comunicación abre el mundo del reconocimiento mutuo; solo en el encuentro con el otro podemos hallar lo que es justo. Este descubrimiento ético del otro arranca en Hegel, para quien el reconocimiento recíproco es el núcleo de la vida social. La tradición de la ética del discurso se basa en que el diálogo implica que reconozcamos en el otro su condición de interlocutor válido con el que establecer un vínculo que nos obliga internamente y que se basa en la idea de que ambos interlocutores se saben mutuamente imprescindibles para dilucidar si una norma es justa. 
Aunque el hombre necesita de la sociedad desde ambas dimensiones, Maritain afirma que la sociedad, la ciudad, está formada por personas, no por individuos. Es decir, la unidad social es la persona. Aunque la persona sea entendida como un todo, de forma necesaria y constitutiva está abierta a la sociedad, es un todo abierto (Maritain, 1942). Por este motivo dirá Maritain que no se puede ser hombre sin vivir entre los hombres: el hombre es un ser político, y la sociedad (tanto familiar como civil) es una exigencia de la naturaleza humana. Esta reflexión antropológica es crucial para el posterior abordaje de la idea de justicia en la obra de Jacques Maritain. La persona necesita de la sociedad y es parte de ella. La sociedad es un todo mayor y mejor que sus partes, y su bien común excede de la suma del bien particular de los individuos que la componen. Pero, por otra parte, la persona -en virtud de su relación con lo absoluto- sobrepasa toda sociedad temporal, y es superior a ella. Desde esta perspectiva, la sociedad y su bien común están subordinados indirectamente al desarrollo completo de la persona y de su dimensión supratemporal.

Este planteamiento podría parecer un tanto paradójico: el ser humano está subordinado al bien común colectivo pero, al mismo tiempo, la colectividad se subordina a él. Maritain aclara esta objeción en Les droits de l'homme et la loi naturelle (1942) con un ejemplo: un atleta, en el momento de la carrera, se focaliza exclusivamente en la competición. Sin embargo, su condición de atleta no agota todas sus dimensiones; fuera de la carrera, existe para el atleta todo un universo personal. Del mismo modo, la persona se orienta enteramente al bien práctico de la sociedad política, pero no en todas sus dimensiones. Como afirma Botturi, ciò mantiene uno spazio di trascendenza della persona rispetto alla totalità politica cui pure intrinsecamente appartiene (Botturi, 1994, p. 25).

\subsection{Libertad}

Decíamos que la idea de individuo remite al mundo material y sensible; de este modo, para Maritain, lo propio de la individuación es la estrechez del ego, ávido de tomar para sí. En tanto que individuos, nuestra unidad es precaria, ya que somos simples fragmentos de una especie (Maritain, 1947). En cambio la personalidad es un misterio más profundo que se enraíza en la subsistencia del espíritu. Para ser descifrado, continúa Maritain, es preciso señalar su relación con el amor, al cual entiende como el síntoma de la presencia de lo absoluto. De este modo, el amor se presenta como auténtico horizonte de perfección del ser humano. En este punto volvemos a encontrar una paradoja: si el amor es constitutivo del ser humano, ¿cómo podemos entenderlo como horizonte de perfección? Maritain lo resuelve afirmando que debemos ganar lo que somos (Maritain, 1947); es decir, es tarea del ser humano aproximar su existencia práctica a su esencia ontológica. ${ }^{3}$ Curcio explica esta cuestión afirmando que la persona no solo se concreta per se subsistens, sino que exige también un per se operans (Curcio, 2010, pp. 41-42).

Esta importante distinción da entrada a la libertad humana en el mismo centro del proceso de comprensión y construcción de la personalidad, ya que -aún siguiendo a Curcio- sin libertad el hombre es un mero individuo, esclavo de los acontecimientos y las circunstancias, incapaz de dirigir su propia vida. Sin libertad, el hombre non sarà che una parte, senza poter pretendere d'essere un tutto (Curcio, 2010, p. 42). Por tanto, existe un papel activo de la persona en la actualización de su propia identidad; en otras palabras, se trata del progresivo avance hacia una aseidad analógica a la divina, hacia una conformidad entre nuestro desenvolvimiento práctico y nuestra esencia entendida como persistencia del espíritu. Evidentemente, este proceso de avance hacia la aseidad -o conquista por parte del hombre de su propia naturaleza esencial o de su propia perfección- es un proceso siempre inacabado. Possenti entiende ese proceso de perfección como una asíntota: l'asintoto del progresso indefinito sarebbe la perfezione (Possenti, 2007, p. 39). Desde esta perspectiva, su carácter de inalcanzable no implica su negación. Para Curcio, este proceso de avance hacia la aseidad tiene que ver, ante todo, con el desarrollo de nuestra capacidad de amar, ya que solo el amor puede ampliar el horizonte de la subjetividad a través de la riqueza del encuentro y la acogida al otro, de la relacionalidad como búsqueda en común del fin último de la vida:

Dunque, una relazione di conformità che diviene il fondamento della verità, ma dove la stessa non può far a meno del primo gradino dell'amore, vero canale di ricerca della verità (Curcio, 2010, p. 42).

En ese proceso, nuestra disyuntiva es seguir la vía de la personalidad o la de la individualidad material. Por eso dirá Maritain que la educación consiste en el difícil arte de hacer crecer la persona y hacer disminuir al individuo. En referencia a este papel activo y la consecuente posibilidad de elección en el ser humano, Maritain distingue tres filosofías de la libertad (Maritain, 1933): 
1.- La primera entiende la libertad como posibilidad de elección, a la que considera como fin en sí misma. Esta concepción es consecuencia de una filosofía liberal - individualista cuyo único límite es la libertad del otro, que no atiende a la justicia ni al bien común y que desemboca en una disolución anárquica de la sociedad. En la terminología utilizada por Bruni y Zamagni, esta concepción se orienta hacia la idea de bien total (Bruni y Zamagni, 2004).

2.- La segunda se basa en una comprensión de la libertad como libertad de autonomía, pero encarnada en el fin supremo del Estado, entendido como un Leviatán que esclaviza a los hombres entregados a él. Se produce así una búsqueda de los fines temporales y el olvido de los intemporales. Esta concepción se orientaría, siguiendo con la terminología de Bruni y Zamagni, hacia el bien colectivo.

3.- La tercera es la perspectiva tomista propuesta también por Maritain. Su planteamiento consiste en que es necesario dotar a los hombres de condiciones más humanas, pero con el fin último de avanzar hacia la libertad final completa. De este modo es posible construir la ciudad, basada en la justicia y la amistad. Desde esta libertad podemos apuntar hacia el bien común (como también se indica en Bruni y Zamagni, 2004).

\subsection{Amor}

Así entendida, la personalidad invita a darse libremente por expansividad y generosidad propias de su estructura ontológica; es decir, la personalidad es fuente de unificación con otras personas "desde dentro". Por tanto, es esencial a la personalidad la comunicación y el amor a los otros. Por eso dirá Maritain en Pour la justice (Maritain, 1945) que, mientras más se entrega el hombre, más intensa es esta vida en él. El filósofo entiende el amor como la capacidad de entregarse; según esta conceptualización, el amor no está referido a las cualidades de la persona amada, sino al centro mismo de la personalidad, que es de naturaleza metafísica, y habilita al ser humano para dar y darse. Así entendido, el amor no tiene por objeto cualidades o esencias, sino personas. De forma clara, Maritain establece un nexo entre donación y existencia, reformulando así el cogito cartesiano:

Pour pouvoir se donner, il faut d'abord exister (Maritain, 1945, p. 191).

Así, el cogito mariteniano bien podría ser: dono me ipsum, ergo sum; me doy, luego existo. Consideramos que este nexo entre don y existencia es uno de los planteamientos más deslumbrantes del filósofo francés. Maritain entiende la llamada al amor, y por tanto al don, como constitutiva del ser humano, marcando en esta dirección su sentido último y su horizonte de desarrollo. Por este motivo, existir como persona está indisolublemente unido a vivir la experiencia del amor y del don de sí. Dicho claramente, la llamada al don en tanto que expresión del amor nos constituye como personas. Nuestra elección es acoger o no esa llamada.

También en Mounier se encuentra un planteamiento semejante; para este, los tres ejercicios esenciales para la formación de la persona son la meditación (que permite descubrir la vocación propia), el compromiso o adhesión a la obra de reconocimiento de la propia encarnación y la renuncia a sí mismo, che è iniziazione al dono di sé e alla vita in altri (Mounier, 1955, p. 128). Es de destacar que Mounier se refiere a estos tres aspectos como requisitos para la formación de la persona, de modo que también en su obra quedan vinculados el don de sí y la existencia de la persona.

Esta experiencia del don de sí abre al ser humano a una nueva perspectiva de encuentro: la propia del vínculo fraterno. Desde la perspectiva del don y el amor, se percibe a las demás personas como "otros sí mismo":

De telle sorte que [la personne] est en quelque manière un univers à soi-même, un microcosme, dans lequel le grand univers tout entier peut être contenu par la connaissance, et qui par l'amour peut se donner tout entier à des êtres qui sont à lui comme d'autres lui-même (Maritain, 1944, p. 188).

La mayor crítica que Maritain hace de la modernidad es que, al ir progresivamente apartando la idea de lo trascendente, se renuncia a un sentido de fin último de la vida humana y a la consecuente vocación de hacer don de sí mismo. De este modo, en la sociedad liberal burguesa se da una vida común sin bien común ni obra común. Pero Maritain no sitúa este planteamiento solo en el contexto de la sociedad liberal-burguesa, sino que lo extiende a las orientaciones sociales del siglo XX. Así, plantea que la sociedad de su tiempo busca la satisfacción de los deseos, sin plantear una reforma interior de la persona. Es precisamente en el vínculo de amor donde el autor sitúa toda posibilidad de emancipación humana, tanto en el orden temporal como en el intemporal. Como afirma Lorenzini,

Se l'uomo fosse completamente lontano dai suoi simili, se fin dalla sua nascita non avesse mai avuto la 
possibilità di comunicare con nessun altro uomo [...] non avrebbe comunque la possibilità di attuare a liveIlo di operazione ciò che principalmente caratterizza la vita umana in quanto propriamente umana (Lorenzini, 1994, p. 178).

Esta necesidad constitutiva de encuentro fraterno en el ser humano es entendida por Maritain como vía de civilización. El término civilización manifiesta un horizonte universal e inclusivo, que trasciende toda cultura y que debe procurar el bien temporal atendiendo a los bienes supratemporales. De este modo, el orden espiritual es libre respecto del temporal, dejando a Dios libre frente al mundo. Esta idea de civilización como construcción universal e inclusiva está también presente en la obra de Bruni y Zamagni (2004). Estos autores contraponen los términos política y civilización del siguiente modo: el término político remite a la polis griega, en la cual solo un porcentaje minoritario de ciudadanos podía formar parte de las instituciones públicas (estaban excluidos los esclavos, siervos, mujeres...). En cambio, el término civilización remite a la idea romana de cives, cuyo carácter es netamente inclusivo. ${ }^{4}$ Aún más, en Roma la idea de felicidad pública no solo iba más allá de la suma de la felicidad individual de los ciudadanos, sino que incluso implicaba la renuncia a la felicidad o la utilidad particular para mejorar la felicidad pública. ${ }^{5}$

Del mismo modo, cuando Maritain se refiere a este horizonte de civilización de la persona humana, recurre al término ciudad. El autor considera que los fundamentos de la ciudad son la justicia y la amistad fraterna; esta será una idea que aparezca de forma reiterada en la obra de Maritain y de otros personalistas, como Lacroix:

Gli antichi stessi vedevano nell'amicizia il fondamento della Città [...]. Nei rapporti giuridici gli individui restano ancora estranei e come esterni gli uni agli altri: essi non si raggiungono direttamente. Al contrario, l'amicizia costituisce gli esseri nella loro personalità ad un tempo indistruttibile ed irreducibile (Lacroix, 1974, pp. 129-130).

Es decir, la ciudad no se articula solo ni principalmente desde la perspectiva de la justicia, sino también desde el vínculo de la amistad fraterna. Por eso dirá Maritain en Pour la justice (Maritain, 1945) que la justicia es la fuerza de conservación [de la ciudad] que permite la amistad cívica. Esto tendrá una enorme relevancia en la reflexión mariteniana sobre la justicia.

\section{CONCLUSIONES}

A la luz de la reflexión planteada, consideramos que cualquier construcción teórica, sea en el ámbito de la sociología, la filosofía, el derecho, la economía, la política, la antropología, o de cualquier rama del saber relativa al hombre, debe atender a la dignidad y los fines que son propios de la persona si quiere ofrecerse como propuesta humanizadora. De lo contrario, estaremos construyendo ámbitos de conocimiento y formas sociales no a la medida de la persona, sino -y esto es lo dramático-formas dadas de antemano a las que la persona debe amoldarse al precio de perder su dignidad y sus fines. Al precio, en otras palabras, de quedar destruida en su identidad genuina, al modo de lo que sucede en el mito griego de Procusto. En palabras de Adolfo Muñoz-Alonso,

La società oggi, piú che una istituzione connaturale alla persona, è una struttura storica, positiva, al di là della persona stessa. Questa concezione della società offende il senso della persona e la possibilità di una promozione progrediente della stessa società. In tal modo quest'ultima si presenta come un'isola, una terra ferma nei confronti della persona (Muñoz-Alonso, 1955, p. 270).

Esta recuperación del concepto de persona convierte la antropología de Jacques Maritain en claramente vigente, dado que esta no solo reivindica la centralidad de la persona y proclama su dignidad a ultranza, sino también porque ofrece un extraordinario equilibrio entre persona y sociedad, y por ende, entre los fines de la persona y los fines de la sociedad, y puede servir para recuperar una reflexión profunda sobre la persona y los fines que le son intrínsecamente propios. Y no solo a nivel teórico abstracto; una de las virtudes del sistema de Maritain es su capacidad para inspirar la actuación concreta de los agentes sociales. En palabras de Papini,

Aunque Maritain vivió en el siglo XX, el de las grandes "narraciones" ideológicas que van del idealismo al marxismo, es un filósofo que pertenece plenamente también al siglo XXI, porque retomando y desarrollando la filosofía de Aristóteles y de Santo Tomás, se confronta con las ideologías modernas e indica caminos que busquen resolver los problemas de nuestro mundo en el respeto a las diferentes culturas y civilizaciones (Papini, 2011, p. 223).

La concepción de persona que acabamos de describir ofrece el punto de partida del humanismo integral que propone el autor: un humanismo que encuentra en la trascendencia la común vinculación de todos los 
hombres, que permite la expansión de su capacidad de amor y entrega, y que Maritain identifica como la más alta posibilidad de desarrollo humano. Este ideal está llamado a concretarse en el orden social mediante la comunión y la construcción de la ciudad fraterna. A este respecto dirá en Christianisme et démocratie (Maritain, 1943) que solo existe un principio de liberación y esperanza: el amor, auténtico vínculo de la ciudad, que desborda sus límites para extenderse a todo el género humano. Esto responde a las inclinaciones más profundas de la naturaleza humana y genera fe en la fraternidad. Esto también supone entender que la obra política por excelencia es construir una casa para los hermanos.

\section{NOTAS}

1 Aunque en obras más recientes de Burgos no aparece esta distinción, nos parece muy acertada, por lo que consideramos pertinente incluirla en este artículo.

2 Botturi ve aquí una clara referencia implícita a la definición de persona de Boecio como rationalis naturae individua substantia (Botturi, 1994).

\section{BIBLIOGRAFÍA}

Alford, H. (2007). Does corporate social responsibility need christian social thought? Notes et documents, 8, pp. 8-16.

Allodi, L. y Gattamorta, L. (2008). Persona in sociologia. Roma: Meltemi.

Álvarez, J. J. (2007). Apuntes para una teoría del saber: la prospectiva de Jacques Maritain. Arbor, 183, 726, pp. 567-579.

Aquino, T. (1971a). De regimine principum. Torino: Marietti.

Aquino, T. (1971b). In libros politicorum Aristotelis expositio (tomo I, libro 1). Torino: Marietti, pp. 112-155.

Aquino, T. (2001). Suma de Teología. Madrid: BAC.

Archer, M. (2000). Being human. The problem of agency. Cambridge: Cambridge University Press. http://dx.doi. org/10.1017/CBO9780511488733

Botturi, F. (1994). Ragion pratica e politica ne personalismo di Jacques Maritain. Divus Thomas, 7, pp. 9-38.

Bruni, L. y Zamagni, S. (2004). Economia civile. Efficienza, equità, felicità pubblica. Bolonia: II Mulino.
3 Con otros términos, caminar hacia la aseidad, según la terminología escolástica.

4 Parece obligado mencionar aquí la narración de Plinio el Viejo de la concesión a todos los habitantes de Hispania de la condición de cives romano: A todas las Hispanias, el emperador Vespasiano Augusto, superadas las turbulencias de la República, concedió el

Burgos Velasco, J. M. (1995). La inteligencia ética. La propuesta de Jacques Maritain. Berna: Peter Lang.

Burgos Velasco, J. M. (1997). ¿Es posible definir el personalismo? En VV.AA. El primado de la persona en la moral contemporánea. Pamplona: Universidad de Navarra, pp. 143-152.

Burgos Velasco, J. M. (2006). Para comprender a Jacques Maritain. Un ensayo históricocrítico. Madrid: Fundación Emmanuel Mounier.

Burgos Velasco, J. M. (2007). Repensar la naturaleza humana. Madrid: Eiunsa.

Cahill, S. (1997). Towards a sociology of the person. Sociological Theory, XVI, 2, pp. 131-148.

Chamming's, L. (2007). Actualité de Humanisme intégral: perspectives pour un nouvel âge de civilisation. Cahiers Maritain, 55, pp. 61-76.

Curcio, G. G. (2010). Benedicto XVI y Jacques Maritain. Una metodologia pedagogica: attraverso la "Caritas in Veritate". Notes et documents no 16.

De Finance, J. (1955). Existence et liberté. París-Lyon: Vitte.
Derecho latino (Plinio el Viejo, Historia Natural, III, 3.30).

5 De este hecho son testimonio muchas biografías de personajes ilustres de la antigua Roma, como la de Agripa, quien a menudo sufragaba obras públicas con sus propios fondos. Resulta evidente lo alejados que estamos actualmente de semejantes concepciones del bien común.
Gattamorta, L. (2012). Persona e sociologia fenomenologica di Max Scheler e Alfred Schütz. En Ferone E. y Germano I. S. (coords.). La persona nella teoria sociologica contemporanea. Torino: Harmattan Italia.

Gruppo Spe (Sociologia per la persona) (2007). La sociologia per la persona. Approfondimenti tematici e prospettive. Milán: Franco Angeli.

Hirschhorn, M. (2007). L'individu social. Autres réalités, autre sociologie? Quebec: Les Presses de l'Université Laval.

Jiménez Garrote, J. L. (2006). Los fundamentos de la dignidad de la persona humana. Bioética, enero-abril 2006, pp. 18-21.

Lacroix, J. (1942). Personne et amour. Lyon: Éditions du Suil. En Rigobello, A. (1978). II personalismo. Roma: Città nuova.

Lacroix, J. (1974). II personalismo come antiideologia. Milán: Vita e Pensiero. En Rigobello, A. (1978). I/ personalismo, Roma: Città Nuova.

Lorenzini, M. (1992). Sussistenza e razionalità nell'antropologia di J. Maritain. Divus Thomas, 1, pp. 164-186. 
Lorenzini, M. (1994) Educazione conquista della libertà. Divus Thomas, 7, pp. 168-196.

Marías, J. (1987). Antropología metafísica. Madrid: Alianza.

Maritain, J. (1933). Du régime temporel et de la liberté. En Oeuvres completes. Friburgo-París: Saint Paul.

Maritain, J. (1942). Les droits de l'homme et la loi naturelle. En Oeuvres completes. Friburgo-París: Saint Paul.

Maritain, J. (1943). Christianisme et démocratie. En Oeuvres completes. Friburgo-París: Saint Paul.

Maritain, J. (1944). Principes d'une politique humaniste. En Oeuvres completes. Friburgo-París: Saint Paul.

Maritain, J. (1945). Pour la justice. En Oeuvres completes. Friburgo-París: Saint Paul.

Maritain, J. (1946). De Bergson a Tomás de Aquino. Buenos Aires: Club de Lectores.

Maritain, J. (1947). La personne et le bien commun. En Oeuvres completes. Friburgo-París: Saint Paul.
Martigniani, L. (2012). Persona tra condizione umana e ontologia sociale realista. En Ferone, E. y Germano, I. La persona nella teoria sociologica contemporanea. Torino: L'Harmattan Italia, pp. 101-122.

Mesa García, R. (2010). La bioética frente a la persona y al individuo. Bioética, mayo-agosto 2010, pp. 18-22.

Mounier, E. (1955). Rivoluzione personalista $e$ comunitaria. Milán: Edizioni di Comunità. En Rigobello, A. (1978). II personalismo. Roma: Città nuova.

Morot-Sir, E. (1971). La pensée française d'aujourd'hui, París: PUF.

Muñoz Alonso, A. (1955). Persona humana y sociedad. Madrid: ed. del Movimiento (1955). En Rigobello, A. (1978). II personalismo. Roma: Città nuova.

Nédoncelle, M. (1959). Verso una filosofia dell'amore e della persona. Roma: Paoline.

Papini, R. (2011). Jacques Maritain, su pensamiento político y el humanismo cristiano hoy. En VV.AA. ¿Hacia una nueva era? Bilbao: Deusto Digital.
Possenti, V. (2007). La nozione di bene comune e l'universalità. Notes et documents, 9, pp. 36-49.

Renouvier, C. (1903). Le personnalisme. París: Alcan. En Rigobello, A. (1978). II personalismo. Roma: Città nuova.

Rigobello, A. (1978). Il personalismo. Roma: Città nuova.

Zanotti, G. J. (2012). Jacques Maritain, su pensamiento político y su relevancia actual. Revista de Instituciones, Ideas y Mercados, 57, pp. 115-139.

Zamagni, S. (2006). La economía como si la persona contara. El papel del principio de comunión en la teoría económica. Stromata, LXII, 1 / 2, pp. 35-60.

Zamagni, S. (2012). Por una economía del bien común. Madrid: Ciudad Nueva. 